\title{
Genetic structuring and fixed polymorphisms in the gene period among natural populations of Lutzomyia longipalpis in Brazil
}

\author{
César Raimundo Lima Costa $\mathrm{Jr}^{1}$, Moises Thiago de Souza Freitas ${ }^{1}$, Carlos Alberto Santiago Figueirêdo Jr ${ }^{1}$, \\ Nádia Consuelo Aragão', Lidiane Gomes da Silva', Carlos Brisola Marcondes², Raimundo Vieira Dias³, \\ Tereza Cristina Leal-Balbino ${ }^{4}$, Manuela Barbosa Rodrigues Souza ${ }^{1}$, Marcelo Ramalho-Ortigão ${ }^{5}$ \\ and Valdir de Queiroz Balbino ${ }^{1 *}$
}

\begin{abstract}
Background: Even one hundred years after being originally identified, aspects of the taxonomy of the sand fly Lutzomyia longipalpis, the principal vector of Leishmania infantum in the Americas, remain unresolved for Brazilian populations of this vector. The diversity of morphological, behavioral, biochemical, and ethological characters, as well as the genetic variability detected by molecular markers are indicative of the presence of a complex of species.

Methods: In this study, a 525 bp fragment of the period gene was used to evaluate sympatric populations of L. longipalpis. A combination of probabilistic methods such as maximum likelihood and genetic assignment approach to investigate sympatric species of L. longipalpis were applied in three populations of Northeast Brazil.

Results: Fixed polymorphisms in geographically isolated populations of L. longipalpis from two localities in the state of Ceará and one in the state of Pernambuco, Brazil, was identified in a 525 bp fragment of the gene period (per). Our results suggest a direct relationship between the number of spots found in males' tergites and the genetic variation in cryptic species of L. longipalpis. The fragment used in this study revealed the nature of the ancestral morphotype $1 \mathrm{~S}$.

Conclusion: New polymorphisms were identified in the gene per which can be used as a genetic barcode to sympatric taxonomy of L. longipalpis. The per gene fragment confirmed the presence of two siblings species of L. longipalpis in Sobral and showed that these same species are present in two other localities, representing an expansion within the L. longipalpis species complex with regards to the states of Ceará and Pernambuco.
\end{abstract}

Keywords: Lutzomyia longipalpis complex, Period gene, Fixed polymorphism

\section{Background}

A species complex is generally defined as a group of morphologically similar species that differ with regards to genetic and ethological aspects [1]. Low flight range and geographic isolation between populations are major drivers of allopatric speciation, contributing to constitution of cryptic species in Phlebotomine sand flies [2-4]. The occurrence of cryptic species is a fairly common

\footnotetext{
* Correspondence: vqbalbino@gmail.com

'Departamento de Genética, Universidade Federal de Pernambuco, Avenida da Engenharia S/N, Cidade Universitária, 50.740-600 Recife, Pernambuco, Brazil

Full list of author information is available at the end of the article
}

event in other disease vectors and have been described in Anopheles gambiae, Culex pipiens, Triatoma dimidiata and phlebotomines [5-8].

Lutzomyia longipalpis, the principal vector of Leishmania infantum, the etiologic agent of American visceral leishmaniasis, has a discontinued distribution throughout the Neotropical region with different populations displaying aspects compatible with those of a species complex $[9,10]$. The existence of cryptic species in the Lutzomyia longipalpis complex was supported by studies using morphological and molecular markers in populations from Central and South America leading to the identification of L. pseudolongipalpis [11], formally recognized 
as the first taxon of the L. longipalpis complex (reviewed by [12]). Later, it was also suggested that $L$. cruzi should be regarded as a cryptic species within the L. longipalpis complex [13].

In Brazil, the presence of a Lutzomyia longipalpis complex was first proposed by Mangabeira [14] and was based on the number of abdominal pale spots, one (1S) or two (2S), visible on abdominal tergites. Analyses of male sexual pheromones and courtship (mating) sounds, as well as microsatellite markers and speciation genes, have provided further evidence of a $L$. longipalpis species complex [10].

The gene period (per) controls biological rhythms and plays a central role in eclosion and insect locomotion activity $[15,16]$. Per has been used in studies of fruit flies (Drosophilidae) population genetics and has been shown to be a useful marker, especially when it comes to identifying cryptic species $[17,18]$. In sand flies, per has also been utilized in studies of population genetics to identify possible members of the L. longipalpis complex in Brazil. Combined with certain behavioral markers (e.g. male mating songs and the types of sexual pheromones produced), analysis of the variability of per suggested the existence of two major population groups of L. longipalpis in Brazil. One group, with at least five species, is found in most localities where L. longipalpis has been reported. This group displays a single spot (1S) on the abdominal tergites, but different pheromones and patterns of pulsating songs. The second group, with two spots (2S), is represented by a single species present in the North, Northeast and Southeast regions of Brazil. Males in this group produce Burst-type songs and the pheromone cembrene-1 [19].

The NE region in Brazil is the region with the highest index of visceral leishmaniasis [20], and studies demonstrated the presence of at least two sister species within L. longipalpis complex [19,21,22]. In Sobral, State of Ceará, these species occur in sympatry and can be separated based either on their abdominal spots $1 \mathrm{~S}$ or $2 \mathrm{~S}$, the different mating songs, the types of pheromones, or the genetic composition of males [23]. Hence, genetic markers related to the abdominal spots may indeed be an important tool for molecular taxonomy of the L. longipalpis complex, especially concerning eco-epidemiological studies to assess potential vectorial capacity between distinct populations.

Here, we investigated the presence of polymorphisms in the gene per and their relatedness to the number of abdominal spots in L. longipalpis males. Sand flies from three localities in the NE of Brazil, separated by distances ranging from $108 \mathrm{~km}$ to as much as $457 \mathrm{~km}$ from each other, were used for our analyses. Four novel fixed single nucleotide polymorphisms (SNP) were identified, some able to separate between the $1 \mathrm{~S}$ and $2 \mathrm{~S}$ flies. In addition, our results point to an ancestral origin of the morphotype 1S. This study contributes to the understanding of the natural history of L. longipalpis populations and provides new insights about the biogeography of this sand fly.

\section{Methods}

Field collection and identification of phebotomine sand flies

Sand fly trappings were carried out in Sobral ( $3^{\circ} 41^{\prime}$ $\left.15^{\prime \prime} \mathrm{S} ; 40^{\circ} 21^{\prime} 5^{\prime \prime} \mathrm{W}\right)$ and Caririaçu $\left(07^{\circ} 02^{\prime} 31^{\prime \prime} \mathrm{S}\right.$; $39^{\circ} 17^{\prime}$ $\left.02^{\prime \prime} \mathrm{W}\right)$ in the State of Ceará, and in Bodocó $\left(07^{\circ} 46^{\prime}\right.$ $\left.42^{\prime \prime} \mathrm{S}, 39^{\circ} 56^{\prime} 28^{\prime \prime} \mathrm{W}\right)$ in the State of Pernambuco, Brazil. All locations included in this study have a BSw'h' climate in accordance to the Köppen climate classification [24], with temperatures ranging from $23^{\circ} \mathrm{C}$ to $36^{\circ} \mathrm{C}$ and low annual rainfall $(936 \mathrm{~mm}$ to $1100 \mathrm{~mm}$ ). The localities included in this study are fully inserted in Caatinga biome, with vegetation composed mainly of ligneous and herbaceous species with high degree of xerophily [25].

Sand flies were trapped in the surrounding houses and domestic animal shelters using five CDC-type miniature light traps positioned at approximately $0.6 \mathrm{~m}$ from the ground. Sand flies were identified according to Young and Duncan [26], and L. longipalpis males were separated based on the number of abdominal spots into $1 \mathrm{~S}$ and $2 \mathrm{~S}$.

\section{DNA extraction, PCR and sequencing}

Genomic DNA was extracted from each specimen using $100 \mu \mathrm{l}$ of Chelex ${ }^{\circ}$ resin (Bio-Rad, Hercules, CA) based on the protocol described by Solano et al. [27] with modifications. Briefly, each sand fly was homogenized using a hand held homogenizer and pestle in $10 \%$ Chelex solution followed by incubation at $56^{\circ} \mathrm{C}$ for an hour. Sample lysates were incubated at $95^{\circ} \mathrm{C}$ for $30 \mathrm{~min}$, centrifuged for $6 \mathrm{~min}$ at $13,000 \times \mathrm{g}$, and each supernatant was removed and stored at $-4^{\circ} \mathrm{C}$.

For each DNA sample isolated, a segment of $525 \mathrm{bp}$ of per [28] was amplified by PCR using the Master Mix kit (Promega, Fitchburg, WI). PCRs were carried out using a PTC-200 thermocycler (MJ Research, Ramsey, MN) as follows: 5 min at $95^{\circ} \mathrm{C}$, and 30 cycles of $95^{\circ} \mathrm{C}$ for $30 \mathrm{sec}-$ onds, $50^{\circ} \mathrm{C}$ for 30 seconds, and $72^{\circ} \mathrm{C}$ for $1 \mathrm{~min}$, with a final extension at $72^{\circ} \mathrm{C}$ for $10 \mathrm{~min}$. A $5 \mu \mathrm{l}$ aliquot from each PCR product was separated on $0.5 \%$ agarose and the remainder was purified using the Genomic DNA Purification Wizard kit (Promega, Fitchburg).

Bi-directional sequencing reactions were performed on each purified PCR product using the BygDye Terminator v3.1 Matrix Standard (Applied Biosystems, Foster City, CA) and analyzed using an ABI3100 Sequence Analyzer (Applied Biosystems, Foster City). Each sample was sequenced in duplicate and the sequences obtained were 
Table 1 Neutrality tests and intra-population genetic diversity measures for each sample

\begin{tabular}{|c|c|c|c|c|c|c|c|}
\hline Samples & Tajima's $D$ & $\mathrm{~N}$ & $\mathrm{Hd}$ & $\pi \pm \mathrm{SE}$ & NS & h & k \\
\hline Bodocó 1S & -1.00443 & 30 & 0.959 & $0.00684 \pm 0.00094$ & 20 & 20 & 3.593 \\
\hline Bodocó 25 & -0.48148 & 24 & 0.986 & $0.00885 \pm 0.00089$ & 20 & 21 & 4.649 \\
\hline Caririaçu 1S & -0.30235 & 28 & 0.997 & $0.01392 \pm 0.00108$ & 31 & 27 & 7.310 \\
\hline Caririaçu $2 S$ & 0.37792 & 31 & 0.994 & $0.01058 \pm 0.00056$ & 20 & 28 & 5.553 \\
\hline Sobral 1S & 0.17037 & 35 & 1.000 & $0.01648 \pm 0.00108$ & 34 & 35 & 8.652 \\
\hline Sobral 2S & 0.46447 & 23 & 0.996 & $0.01162 \pm 0.00089$ & 20 & 22 & 6.103 \\
\hline Total & -0.05022 & 171 & 0.997 & $0.01901 \pm 0.01901$ & 55 & 149 & 9.980 \\
\hline
\end{tabular}

Tajima's D; Tajima test of neutrality; N: sample size; HD: Haplotypic diversity; $\pi \pm$ SE: nucleotide diversity and standard errors (SE); NS, Number of polymorphic sites; h, Haplotypes; K, average number of nucleotide differences. ${ }^{*} p, 0.05$.

assembled and analyzed with the Staden package [29] based on the values of Phred 40 [30]. The high-quality sequences obtained were deposited in GenBank (accession numbers KF479047-KF479163 and KP013849-KP013902).

\section{Population genetics}

Sequence alignment was performed using the program ClustalW (MEGA v.5.1), and the conserved and variables sites (parsimony informative and singletons sites) also were verified using MEGA v.5.1 [31]. The analyses of polymorphisms and the neutrality tests were performed using DnaSP 5.10.1 [32]. For optimal viewing of polymorphisms, parsimony-informative sites were exported to compose sequence logos obtained by Weblogo v. 3.2 [33].

The genetic structuring of the L. longipalpis populations was verified using sequences alignment throughout STRUCTURE v.2.3 [34], with model-based approach. This algorithm clusters individuals into populations. The assigned proportion of each individual belonging to each population (membership coefficient Q) was estimated using Bayesian statistics and Markov Chain Monte Carlo simulations (MCMC). MCMC simulations were performed with 100,000 interactions of burn-in period and followed by one million steps. For each value of $\mathrm{K}$ (1 to 10), 10 interactions were performed

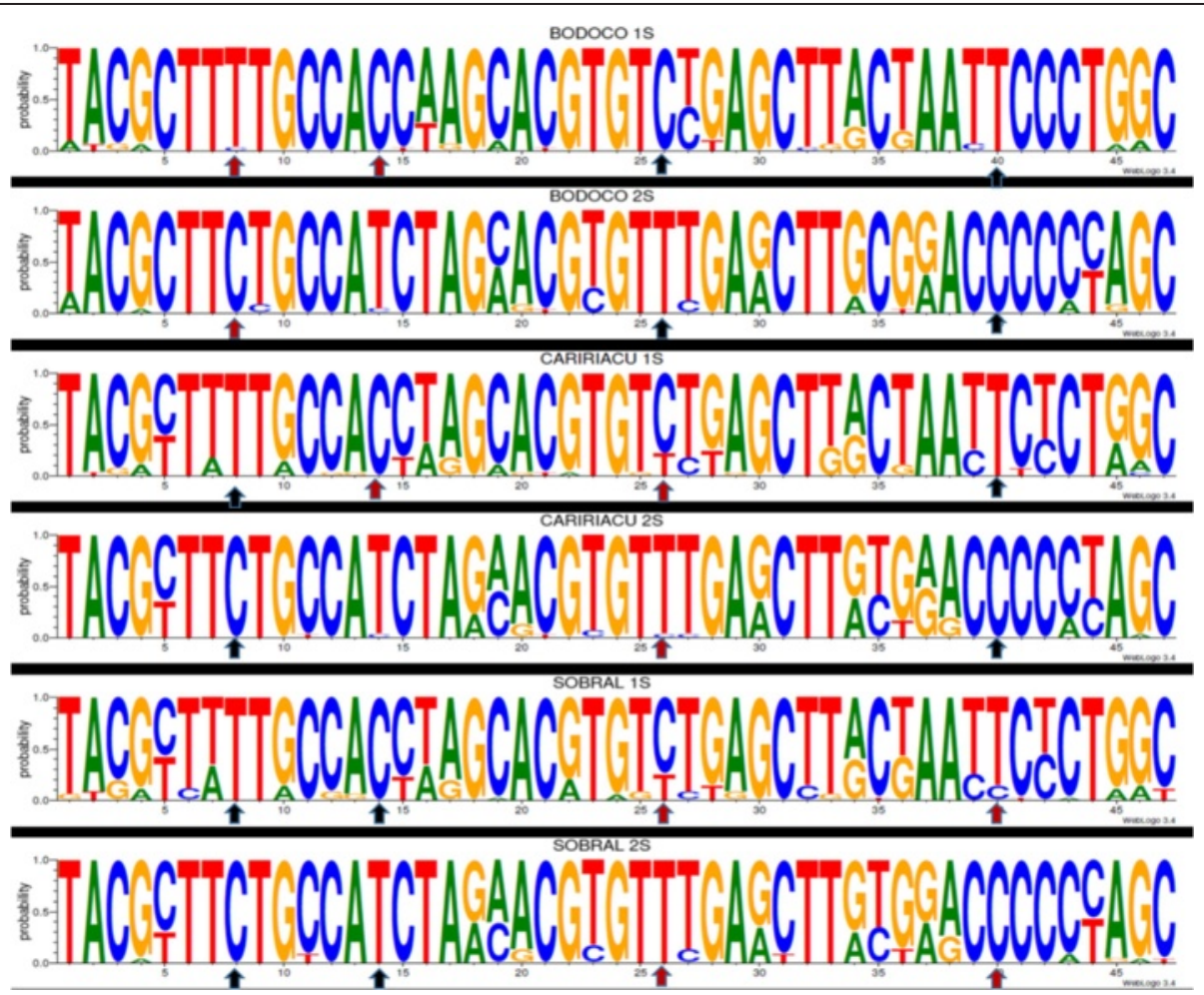

Figure 1 Schematic representation of polymorphisms of a fragment of $\mathbf{5 2 5} \mathbf{b p}$ of the gene period using Weblogo [33]. Shown are the sequences obtained from L. longipalpis collected in Bodocó, State of Pernambuco (Bodocó 1S and Bodocó 2S) and Caririaçu and Sobral, State of Ceará, Brazil. Font size is indicative of the frequency of a nucleotide at any given site. Fixed (black arrows) and partially fixed (red arrows) SNPs are indicated. 
in order to estimate the $\mathrm{K}$ values, and the most likely population (or cluster) number was determined by the $\Delta \mathrm{K}$ analysis [35]. Matched Fst and $\mathrm{MN}$ values [36] were obtained through the Arlequin v.3.1 software
[37], using 1000 random permutations. Population structure was verified by the utilization of AMOVA [37], based on the evaluation of different hierarchical groups.

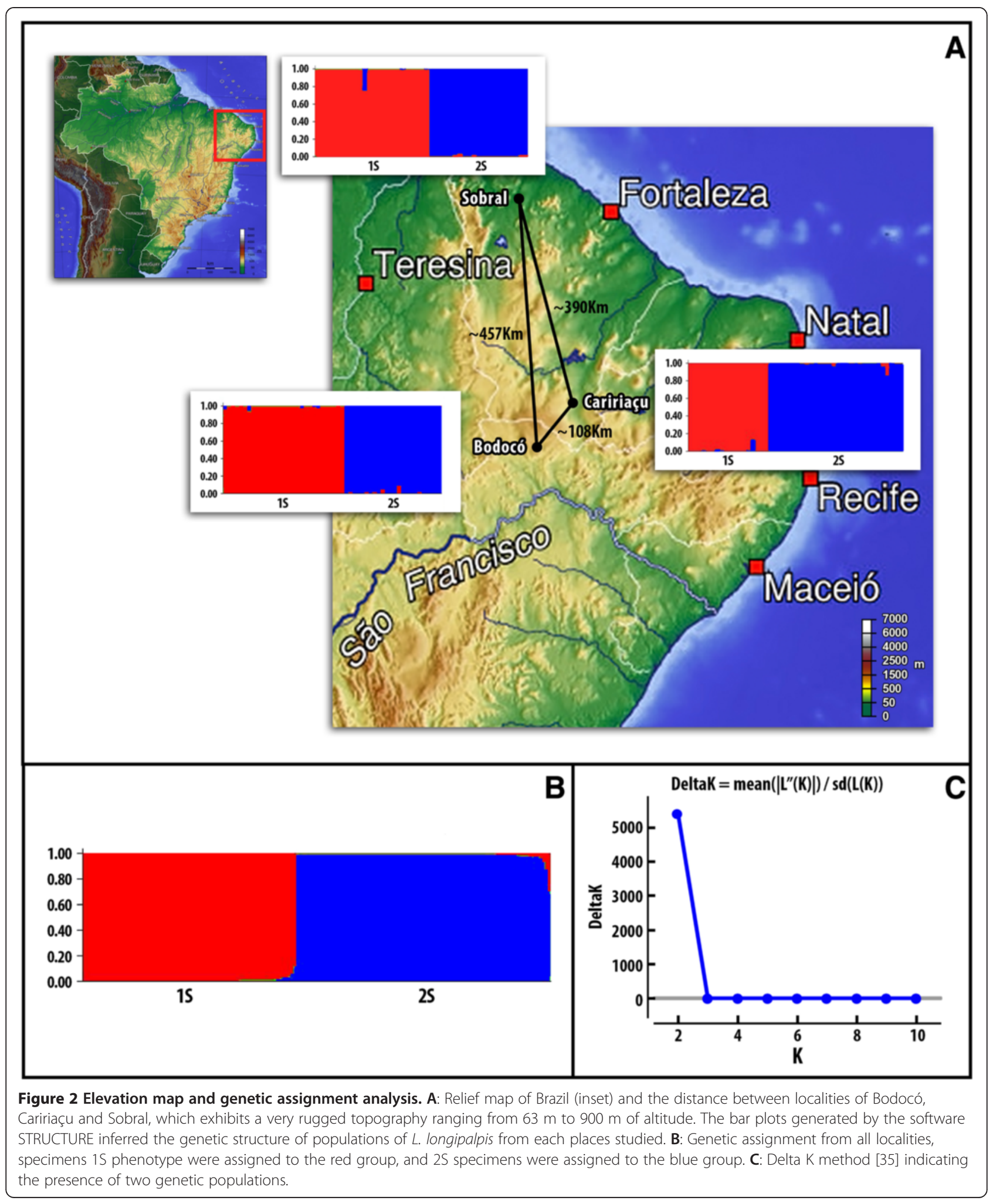




\section{Phylogenetic analysis}

For the UPGMA tree, the Fst values were imported into MEGA V. 5.1 software. The jModeltest v.0.1.1 software was used to select the best-fit DNA substitution model for ML analysis based on the Akaike information criterion (AIC) algorithm [38]. The best-fit model for the per sequence analyzed was the $T V M+I+G$. The maximum likelyhood (ML) tree for per sequences was calculated using PhyML v. 3.0 [39].

\section{Results}

Following identification and sequencing of the sand flies collected, we obtained a total of 171 sequences of the gene per from L. longipalpis males, being 58 (35 1S and 23 2S) from Sobral, 59 (28 1S and $312 S$ ) from Caririaçu, and 54 (30 1S and 24 2S) from Bodocó. Tests such as Tajima's neutrality, haplotype diversity, nucleotide diversity, and average number of nucleotide differences for each population studied are summarized in Table 1. Analysis of the parsimony informational sites identified four fixed single nucleotide polymorphisms (SNP) within the $525 \mathrm{bp}$ fragment of per used in our analyses. All SNPs can be utilized to separate phenotypes. The SNP identified on nucleotide position T124C (the first and second nucleotides occur in $1 \mathrm{~S}$ and $2 \mathrm{~S}$ phenotypes, respectively) located within exon 1 , is fixed in $L$. longipalpis from both localities in Ceará. The SNP identified in position C424T (within exon 2) is fixed in the L. longipalpis from Bodocó and Caririaçu. The SNP at position C171T also separates the two phenotypic forms (1S and $2 \mathrm{~S}$ ) and is fixed in L. longipalpis from Sobral only. In contrast, the SNP at position T256C, which also separates $1 \mathrm{~S}$ from $2 \mathrm{~S}$, is present in the L. longipalpis from Bodocó only (Figure 1).

In the genetic assignment analyses of L. longipalpis, with each population assessed separately, two distinct genetic groups associated with abdominal spots were observed and each sequence possessing a probability (Q) greater than $80 \%$ to belong to each genetic group (Figure 2A). When sequences from all three places were combined, the genetic assignment test indicated the presence of two genetic groups associated with $1 \mathrm{~S}$ and $2 \mathrm{~S}$ morphotypes, as suggested by the peak of $\Delta \mathrm{k}$ indicating the presence of two genetically distinct populations (Figure $2 \mathrm{~B}$ and $2 \mathrm{C}$, respectively).

Similarly, when Fst was used to verify the genetic structuring in the three localities (Bodocó, Caririaçu and Sobral), the presence of two morphotypes related to $1 \mathrm{~S}$ and $2 \mathrm{~S}$ were again observed. The L. longipalpis $1 \mathrm{~S}$ populations of Bodocó, Caririaçu and Sobral display low Fst values when compared to each other, forming a genetically similar group (Group $1 S$ ). A similar pattern was observed when comparing the $2 \mathrm{~S}$ populations amongst themselves. However, the Fst value were the highest when comparing different phenotypes, even from the same location (Table 2). The tree of distances obtained from Fst values exhibited a phylogeographic profile with Bodocó population more distant from Ceará populations, when comparing pairs of phenotypes (Figure 3). Utilizing these groups, AMOVA showed significantly the highest percentage of variation between $1 \mathrm{~S}$ and $2 \mathrm{~S}$ groups (Table 3).

The maximum likelihood tree showed a geographical separation between taxons. Although, the phenotypic groups were separated, indicating an ancestral nature of the $1 \mathrm{~S}$ clade, supported by the monophylic nature of the $2 \mathrm{~S}$ group with $55 \%$ bootstrap value (Figure 4).

\section{Discussion}

The composition of the L. longipalpis complex is still a rather controversial topic even though the distribution of this sand fly in Brazil strongly suggests the presence of at least five species as part of this complex [10,19].

Our assessment of polymorphism frequency in the per gene in different populations of L. longipalpis revealed for the first time the presence of two fixed polymorphisms (124 and 424) that can reliably be used to separate $1 \mathrm{~S}$ and $2 \mathrm{~S}$ phenotypes. The SNP at position T124C was previously reported in L. longipalpis populations collected in the town of Jaíba, Minas Gerais, located $1,347 \mathrm{~km}$ from Sobral and $1,040 \mathrm{~km}$ from Caririaçu [19]. The SNP at position C424T was identified

Table 2 Genetic differentiation among samples

\begin{tabular}{llllllll}
\hline Populations & & $\boldsymbol{F}_{\text {st }}$ & Nm & Dxy & Da & Ss & Sf \\
\hline Sobral 1S & Caririaçu 1S & 0.01892 & 2.86330 & 0.01549 & 0.00029 & 26 & 0 \\
Sobral 1S & Sobral 2S & 0.50016 & 2.73255 & 0.02787 & 0.01382 & 11 & 2 \\
Sobral 1S & Caririaçu 2S & 0.48584 & 0.25225 & 0.02611 & 0.01258 & 9 & 1 \\
Caririaçu 1S & Sobral 2S & 0.53515 & 0.27071 & 0.02723 & 0.01445 & 9 & 3 \\
Caririaçu 1S & Caririaçu 2S & 0.52220 & 0.28603 & 0.02542 & 0.01317 & 9 & 2 \\
Sobral 2S & Caririaçu 2S & 0.00000 & 27.22473 & 0.01097 & 0.00000 & 16 & 0 \\
Bodocó 1S & Sobral 1S & 0.15423 & 0.51128 & 0.01379 & 0.00213 & 16 & 0 \\
Bodocó 1S & Caririaçu 1S & 0.15249 & 0.52877 & 0.01225 & 0.00187 & 16 & 0 \\
Bodocó 1S & Bodocó 2S & 0.66122 & 0.54558 & 0.02317 & 0.01532 & 8 & 2 \\
Bodocó 1S & Sobral 2S & 0.64012 & 0.41809 & 0.02566 & 0.01642 & 7 & 3 \\
Bodocó 1S & Caririaçu 2S & 0.63698 & 0.44627 & 0.02399 & 0.01528 & 6 & 1 \\
Bodocó 2S & Sobral 1S & 0.50950 & 0.46142 & 0.02583 & 0.01316 & 7 & 1 \\
Bodocó 2S & Caririaçu 1S & 0.54926 & 4.08197 & 0.02527 & 0.01388 & 8 & 2 \\
Bodocó 2S & Sobral 2S & 0.10863 & 4.21053 & 0.01149 & 0.00125 & 12 & 0 \\
Bodocó 2S & Caririaçu 2S & 0.10793 & inf & 0.01089 & 0.00118 & 12 & 0 \\
\hline
\end{tabular}

$F_{\mathrm{st}}$ : pair-wise genetic differentiation; $\mathrm{Nm}$ : number of migrants per generation; Dxy: average number of nucleotide substitutions per site between populations; Da: number of net nucleotide substitutions per site between populations; Ss: number of shared polymorphisms between pairs of population; Sf: number of fixed differences between pairs of populations. 

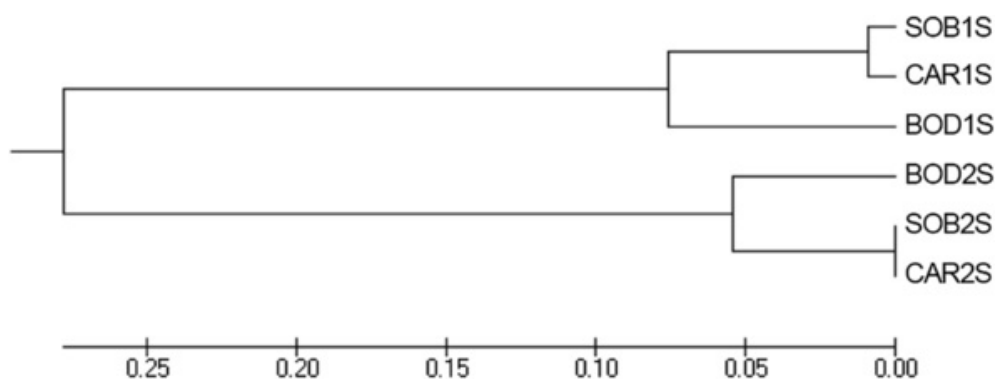

Figure 3 AMOVA UPGMA tree for populations of $\boldsymbol{L}$. longipalpis. UPGMA tree constructed from the Fst values for each phenotype and their respective localities. Populations of Sobral and Caririaçu 1S and 2S (SOB1S, SOB2S, CAR1S and CAR2S) are separate populations of Bodocó (BOD1S and BOD2S).

in L. longipalpis populations from Bodocó and Caririaçu. Two additional SNPs, at positions C171T and T256C can be used as coadjuvants to separate between the $1 \mathrm{~S}$ and $2 \mathrm{~S}$ L. longipalpis morphotypes from Sobral and Bodocó, respectively. Although all polymorphisms are synonymous, the combined SNPs can be used as markers for cryptic species in L. longipalpis.

The importance of the ML method for the detection of recent speciation events also was previously shown [40-42]. The Bayesian and ML approaches for L. longipalpis collected in Bodocó, Caririaçu and Sobral indicate the presence of two genetically separated populations, and that each collected sample belongs to either $1 \mathrm{~S}$ or $2 \mathrm{~S}$ morphotype. Our analyses also indicated that these two genetically distinct populations are related to abdominal spots, as previously suggested for sympatric populations of L. longipalpis [21-23].

Analysis the $525 \mathrm{bp}$ fragment of per in sand flies from Sobral showed greater separation between the two morphotypes, even when genetic distance methodology was used (Additional file 1: Figure S1). A Neighbor-joining tree added to the population genetic structure analyses confirmed the presence of cryptic species occurring in sympatry in Sobral, as noted by Bauzer et al. [23]. In that case, the presence of a haplotype shared by distinct

Table 3 AMOVA results for L. longipalpis populations

\begin{tabular}{|c|c|c|}
\hline Source of variation & d.f. & Percentage of variation \\
\hline Among groups & 1 & 50.69 \\
\hline Among populations within groups & 4 & 4.28 \\
\hline Within populations & 165 & 45.04 \\
\hline Total & 170 & \\
\hline $\begin{array}{l}\mathrm{F}_{\mathrm{SC}} \text { (haplotypes/populations } \\
\text { within groups) }\end{array}$ & & 0.08672 \\
\hline FST $_{\text {ST }}$ (holypes/populations/groups) & & 0.54963 \\
\hline $\mathrm{F}_{\mathrm{CT}}$ (populations/groups) & & 0.50687 \\
\hline
\end{tabular}

Phenotype Groups: 1S (Bodocó 1S, Caririaçu 1S and Sobral 1S), and 2S (Bodoco 2S, Caririaçu 2S and Sobral 2S). morphotypes was observed. In contrast, our analyses using a greater number of polymorphisms revealed patterns of total association between phenotypes and genotypes $[22,43]$.

As the number of shared haplotypes observed was lower in the 525 bp fragment of per in comparison to the 266 bp fragment (15 shared haplotypes versus 26, Additional file 2: Table S1), it was suggestive of the ability of the 525 bp per to detect greater genetic variation in L. longipalpis populations. Analyses by AMOVA of the results obtained with the $525 \mathrm{bp}$ fragment confirmed a greater variation between phenotypically distinct groups characterized by the association of a pattern of abdominal spots and the genetic marker not previously reported for $L$. longipalpis populations.

In Sobral, L. longipalpis is described as distinct populations of two sympatric species, and commonly separated by the $1 \mathrm{~S}$ and $2 \mathrm{~S}$ phenotypes. Genetic markers, copulatory sounds, and sex pheromones have been characterized for each of the L. longipalpis populations found in Sobral and have been used to confirm the separation conferred by the $1 \mathrm{~S} / 2 \mathrm{~S}$ phenotypes $[19,23,44,45]$. Conversely, L. longipalpis collected in the localities of Bodocó and Caririaçu are, according to our data, two genetically distinct populations, and the results observed, match the pattern of abdominal spots described in the sympatric populations [22,23,43]. Thus, as L. longipalpis from Bodocó and Caririaçu exhibit the same phenotypic and genetic patterns of populations found in Sobral, it is likely that these two populations also share chemical and behavioral characteristics similar to what was previously described for the L. longipalpis found in Sobral.

Our group previously reported on a secondary contact between L. longipalpis populations that were separated by the original course of the São Francisco River [46]. This secondary contact between the $1 \mathrm{~S}$ populations of the Brazilian SE and NE may have promoted the genetic diversity of $1 \mathrm{~S}$. It also further reinforced the hypothesis that $2 \mathrm{~S}$ actually derives from $1 \mathrm{~S}$, in accordance to the maximum likelihood tree. 


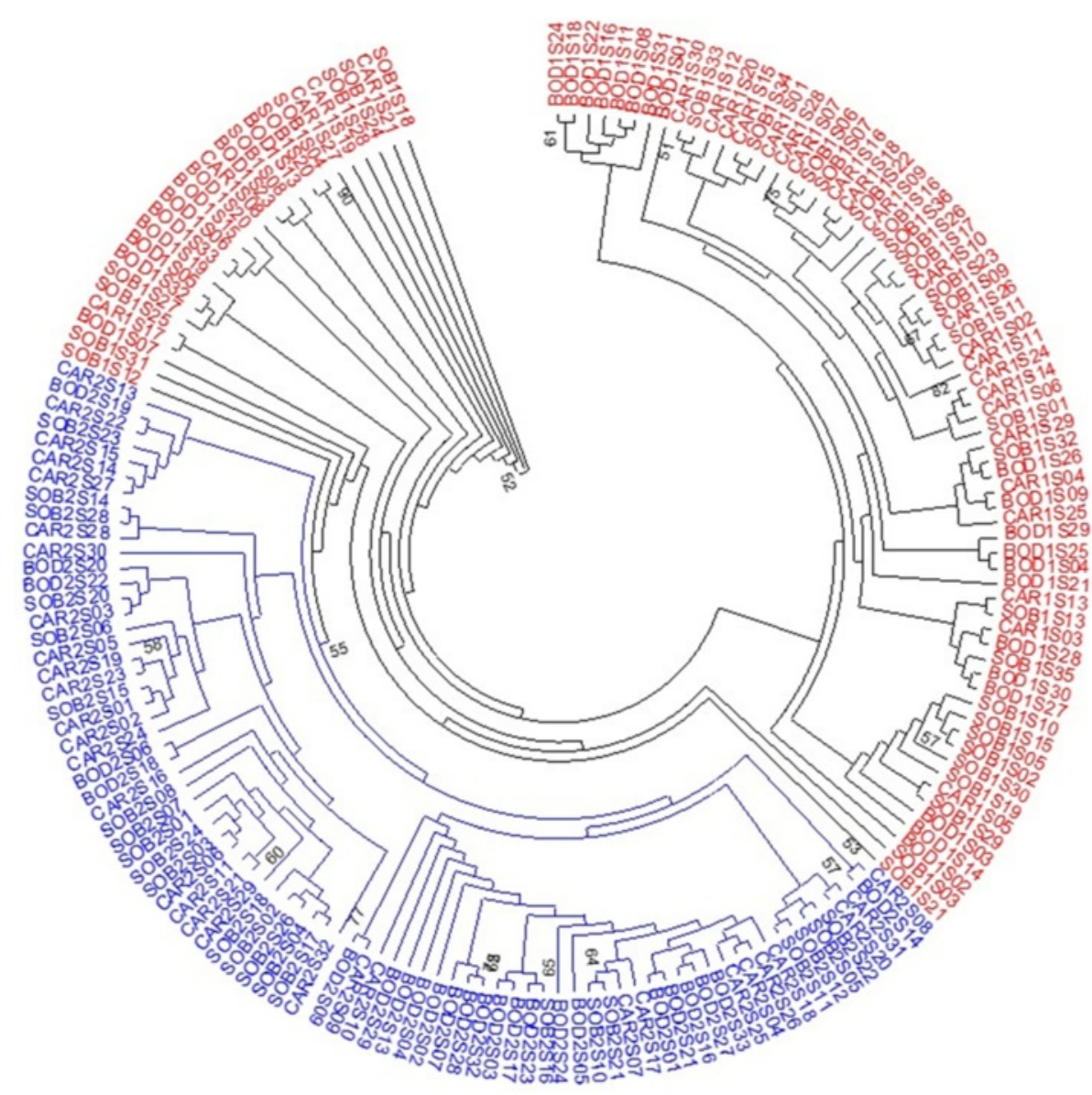

Figure 4 Maximum likelihood tree obtained of the $T V M+I+G$ model has shown the results of using $\mathbf{5 2 5}$ bp from Lutzomyia longipalpis period marker. The localities of Bodocó (BOD), State of Pernambuco and Caririaçu (CAR) and Sobral (SOB), State of Ceará, Brazil. The topology shown (55\% bootstrap support) consistently separates the two morphological variants known for L. longipalpis, the morphotypes $1 S$ and 2 S, as well as puts in evidence the derived monophyletic position of the 25 group.

\section{Conclusion}

Understanding the complex population genetics of $L$. longipalpis and its pattern of distribution is critical in areas with high endemicity for the transmission of visceral leishmaniasis, such as the current situation in the state of Ceará in Brazil. The genetic analyses using the $525 \mathrm{bp}$ fragment of the per gene revealed for the first time a moderate geographical structuring between the L. longipalpis populations, and a significant variability with regards to the $1 \mathrm{~S}$ and $2 \mathrm{~S}$ phenotypes. The results presented here also underscore the importance of the abdominal spots for the diagnosis of cryptic species of sympatric populations of the L. longipalpis complex in Brazil, and the use of per as an important barcode marker to populations of $L$. longipalpis. Further confirmation of the fixed SNPs identified in per and its application as taxonomic markers to differentiate sympatric L. longipalpis populations across Brazil is warranted.

\section{Ethical approval}

Ethical approval was not required for the current study.

\section{Additional files}

Additional file 1: Figure S1. Neighbor-joining phylogenetic tree of the L. longipalpis. Tree was constructed using the $525 \mathrm{bp}$ fragment of the gene period obtained by PCR amplification of DNA extracted from L. longipalpis collected in Sobral, State of Ceara, Brazil. The tree shows the two phenotypic forms (1S and 2S) with bootstrap value of $67 \%$. The parameters used for the reconstruction of the cladogram were the same as in Bauzer et al. [23].

Additional file 2: Table S1. Haplotypes frequency. Frequency of haplotypes generated with the fragment of 266 and 525 base pairs.

\section{Competing interests}

The authors declare that they have no competing interests.

\section{Authors' contributions}

VQB and CRLCJ designed and supervised the study; MTSF, CASFJ, NCA, LGS, RVD, TCLB performed the bioinformatics and molecular analyses; CBM, MBRS, 
MRO revised the manuscript; $V Q B, C R L C J$ revised the final version of the manuscript. All authors read and approved the final manuscript.

\section{Acknowledgments}

This study was supported by Fundação de Amparo à Ciência e Tecnologia do Estado de Pernambuco (APQ-0651-2.02/10), and Ministério da Saúde, Brazil (TC 300/2013). VQB was supported by CNPq, Grant Number 309124/ 2012-3. We are also grateful to the Secretaria de Saúde do Município de Sobral for assistance and logistic support.

\section{Author details}

${ }^{1}$ Departamento de Genética, Universidade Federal de Pernambuco, Avenida da Engenharia S/N, Cidade Universitária, 50.740-600 Recife, Pernambuco, Brazil. ²Departamento de Microbiologia, Imunologia e Parasitologia, Universidade Federal de Santa Catarina, Campus Reitor João David Ferreira Lima, 88040-900 Florianópolis, Santa Catarina, Brazil. ${ }^{3}$ Centro de Controle de Zoonoses, Rua Finlândia S/N, Parque Silvana II, 62010-970 Sobral, Ceara, Brazil. ${ }^{4}$ Departamento de Microbiologia, Centro de Pesquisas Aggeu Magalhaes, Avenida Professor Moraes Rego S/N, Cidade Universitária, 50740-465 Recife, Pernambuco, Brasil. ${ }^{5}$ Department of Entomology, Kansas State University, W. Waters Hall 123, 66506-400 Manhattan, KS, USA.

\section{Received: 31 October 2014 Accepted: 5 March 2015} Published online: 01 April 2015

\section{References}

1. Bickford D, Lohman DJ, Sodhi NS, Ng PKL, Meier R, Winker K, et al. Cryptic species as a window on diversity and conservation. Trends Ecol Evol. 2007:22:148-55. doi:10.1016/j.tree.2006.11.004.

2. Alexander JB. Dispersal of phlebotomine sand flies (Diptera: Psychodidae) in a Colombian coffee plantation. J Med Entomol. 1987;24:552-58.

3. Morrison AC, Ferro C, Tesh RB. Host preferences of the sand fly Lutzomyia longipalpis at an endemic focus of american visceral leishmaniasis in Colombia. Am J Trop Med Hyg. 1993;49:68-75.

4. Cohnstaedt LW, Beati L, Caceres AG, Ferro C, Munstermann LE. Phylogenetics of the phlebotomine sand fly group verrucarum (Diptera: Psychodidae: Lutzomyia). Am J Trop Med Hyg. 2011;84:913-22.

5. Anderson TJC, Haubold B, Williams JT, Estrada-Franco JG, Richardson L, Mollinedo $\mathrm{R}$, et al. Microsatellite markers reveal a spectrum of population structures in the malaria parasite Plasmodium falciparum. Mol Biol Evol. 2000;17:1467-82

6. Krzywinski J, Besansky NJ. Molecular systematics of Anopheles: from subgenera to subpopulations. Annu Rev Entomol. 2003;48:111-39.

7. Adler PH, Cheke RA, Post RJ. Evolution, epidemiology, and population genetics of black flies (Diptera: Simuliidae). Infect Genetic Evol. 2010;10:846-65. doi:10.1016/j.meegid.2010.07.003

8. Monteiro F, Peretolchina T, Lazoski C, Harris K, Dotson E. Phylogeographic pattern and extensive mitochondrial DNA divergence disclose a species complex within the Chagas disease vector Triatoma dimidiata. PLoS One. 2013;8:e70974

9. Lainson R, Rangel EF. Lutzomyia longipalpis and the eco-epidemiology of American visceral leishmaniasis, with particular reference to Brazil. Mem Inst Oswaldo Cruz. 2005:100:811-27.

10. Bauzer LGSR, Souza NA, Maigon RDC, Peixoto AA. Lutzomyia longipalpisin Brazil: a complex or a single species? A mini-review. Mem Inst Oswaldo Cruz. 2007;102:1-12.

11. Arrivillaga JC, Feliciangeli MD. Lutzomyia pseudolongipalpis: the first new species within the longipalpis (Diptera: Psychodidae: Phlebotominae) complex from La Rinconada, Curarigua, Lara State, Venezuela. J Med Entomol. 2001;138:783-90.

12. Soares RP, Turco SJ. Lutzomyia longipalpis (Diptera: Psychodidae: Phlebotominae): a review. An Acad Bras Cienc. 2003;75:301-30.

13. Vigoder FM, Araki AS, Bauzer LGSR, Souza NA, Brazil RP, Peixoto AA. Lovesongs and period gene polymorphisms indicate Lutzomyia cruzi (Mangabeira, 1938) as a sibling species of the Lutzomyia longipalpis (Lutz and Neiva, 1912) complex. Infec Gen Evol. 2010;10:734-39. doi:10.1016/j. meegid.2010.05.004

14. Mangabeira O. Sobre a sistemática e biologia dos Phlebotomus do Ceará. Rev Bras Malar Doenç Trop. 1969;21:3-26.
15. Hardin PE, Hall JC, Rosbash M. Feedback of the Drosophila period gene product on circadian cycling of its messenger RNA levels. Nature. 1990;343 (6258):536-40

16. Dunlap JC. Molecular bases for circadian clocks. Cell. 1999;96(2):271-90. doi:10.1016/S0092-8674(00)80566-8.

17. Rosato E, Peixoto AA, Barbujani G, Costa R, Kyriacou CP. Molecular evolution of the period gene in Drosophila simulans. Genetics. 1994;138:693-707.

18. Sawyer LA, Sandrelli F, Pasetto C, Peixoto AA, Rosato E, Costa R, et al. The period gene Thr-Gly polymorphism in Australian and African Drosophila melanogaster populations: implications for selection. Genetics. 2006;174:465-80.

19. Araki AS, Vigoder FM, Bauzer LGSR, Ferreira GEM, Souza NA, Araújo IB, et al. Molecular and behavioral differentiation among brazilian populations of Lutzomyia longipalpis (Diptera: Psychodidae: Phlebotominae). PLoS Negl Trop Dis. 2009;3:1-12.

20. Ministério da Saúde. 2013. http://portalsaude.saude.gov.br/images/pdf/2014/ setembro/09/LV-Casos.pdf.

21. Lins RM, Souza NA, Brazil RP, Maingon RD, Peixoto AA. Fixed differences in the paralytic gene define two lineages within the Lutzomyia longipalpis complex producing different types of courtship songs. PLoS One. 2012;7: e44323.

22. Silva MH, Nascimento MDSB, Leonardo FS, Rebêlo JMM, Pereira SRF. Genetic differentiation in natural populations of Lutzomyia longipalpis (Lutz \& Neiva) (Diptera: Psychodidae) with different phenotypic spot patterns on tergites in males. Neotrop Entomol. 2011;40:501-6.

23. Bauzer LG, Souza NA, Ward RD, Kyriacou CP, Peixoto AA. The period gene and genetic differentiation between three Brazilian populations of Lutzomyia longipalpis. Insect Mol Biol. 2002;11:315-23.

24. Peel MC, Finlayson BL, McMahon TA. Updated world map of the Koppen Geiger climate classification. Hydrol Earth Syst Sci. 2007;11:1633-44.

25. Pennington RT, Prado DE, Pendry CA. Neotropical seasonally dry forests and Quaternary vegetation changes. J Biog. 2000;27(2):261-73.

26. Young DG, Duncan MA. Guide to the identification and geographic distribution of Lutzomyia sand flies in Mexico, the West Indies, Central and South America (Diptera: Psychodidae). Memoirs of the Am Entom Inst. 1994;54:1-881.

27. Solano P, Duvallet G, Dumas V, Cuisance D, Cuny G. Microsatellite markers for genetic population studies in Glossina palpalis (Diptera: Glossinidae). Acta Trop. 1997:65:175-80.

28. Mazzoni CJ, Gomes CA, Souza NA, De Queiroz RG, Justiniano SCB, Ward RD, et al. Molecular evolution of the period gene in sandflies. J Mol Evol. 2002;55:553-62.

29. Standen R. The Staden sequence analysis package. Mol Biotechnol. 1996:5:233-41.

30. Ewing $B$, Green P. Base-calling of automated sequencer traces using Phred? II. Error? Probabilities. Genome Res. 1998:8:186-94.

31. Tamura K, Peterson D, Peterson N, Stecher G, Nei M, Kumar S. MEGA 5: molecular evolutionary genetics analysis using maximum likelihood, evolutionary distance, and maximum parsimony methods. Mol Biol Evol. 2011;10:2731-39. doi:10.1093/molbev/msr121.

32. Rozas J, Rozas R. DnaSP version 3: an integrated program for molecular population genetics and molecular evolution analysis. Bioinformatics. 1999;15:174-75.

33. Crooks GE, Hon G, Onchandia JM, Brenner SE. WebLogo: a sequence logo generator. Genome Res. 2004;14:1188-90.

34. Pritchard JK, Stephens P, Donnelly P. Inference of population structure using multilocus genotype data. Genetics. 2000;155:945-59.

35. Evanno G, Regnaut $\mathrm{S}$, Goudet J. Detecting the number of clusters of individuals using the software structure: a simulation study. Mol Ecol. 2005;14:2611-20

36. Rousset F. Genetic differentiation and estimation of gene flow from $F$ statistics under isolation by distance. Genetics. 1997;145:1219-28.

37. Excoffier L, Laval G, Schneider S. Arlequin ver. 3.0: an integrated software package for population genetics data analysis. EvolBioinform Online. 2005;1:47-50.

38. Posada D. jModel test: phylogenetic model averaging. Mol Biol Evol. 2008:25:1253-56.

39. Guindon S, Gascuel O. A simple, fast, and accurate algorithm to estimate large phylogenies by maximum likelihood. Syst Biol. 2003;52:696-704.

40. Passamonti M, Mantovani B, Scali V. Phylogeny and karyotype evolution of the Iberian Leptyniaattenuata species complex (Insecta: Phasmatodea). Mol Phylogenet Evol. 2004;30:87-96. 
41. Lehr MA, Kilpatrick CW, Wilkerson RC, Conn E. Cryptic species in the Anopheles (Nyssorhynchus) albitarsis (Diptera: Culicidae) complex: incongruence between random amplified polymorphic dna-polymerase chain reaction identification and analysis of mitochondrial DNA COI gene sequences. Ann Entomol Soc Am. 2005;98:908-17.

42. Wilkerson RC, Foster PG, Li C, Sallum MAM. Molecular phylogeny of neotropical Anopheles (Nyssorhynchus) albitarsis species complex (Diptera: Culicidae). Ann Entomol Soc Am. 2005;98:918-25.

43. Lins RMMA, Souza NA, Peixoto AA. Genetic divergence between two sympatric species of the Lutzomyia longipalpis complex in the paralytic gene, a locus associated with insecticide resistance and love song production. Mem Inst Oswaldo Cruz. 2008;103:736-40.

44. Hamilton JGC, Maingon R, Alexander B, Ward R, Brazil RP. Analysis of the sex pheromone extract of individual male Lutzomyia longipalpis sandflies from six regions in Brazil. Med Vet Entomol. 2005;19:480-88.

45. Souza NA, Vigoder FM, Araki AS, Ward RD, Kyriacou CP, Peixoto A. Analysis of the copulatory courtship songs of Lutzomyia longipalpis in six populations from Brazil. J Med Entomol. 2004;41:906-13.

46. Coutinho-Abreu IV, Sonoda IV, Fonseca JA, Melo MA, Balbino VQ. Lutzomyia longipalpis s.l. in Brazil and the impact of the Sao Francisco River in the speciation of this sand fly vector. Parasit Vectors. 2008;1:16.

\section{Submit your next manuscript to BioMed Central and take full advantage of:}

- Convenient online submission

- Thorough peer review

- No space constraints or color figure charges

- Immediate publication on acceptance

- Inclusion in PubMed, CAS, Scopus and Google Scholar

- Research which is freely available for redistribution 